\title{
Using the Delphi technique to determine objectives and topical outline for a pharmaceutical care course: an experience from the Cuban higher education system
}

\author{
Alina M. Martínez-Sánchez ${ }^{1,2}$ (D)
}

\begin{abstract}
Background: Being pharmaceutical care one of the four areas defined by the International Pharmaceutical Federation's Global Competence Framework, the curriculum redesigned scheme is a priority task to perform a pharmaceutical workforce capable to contribute significantly to the appropriate use of medicines. Therefore, the pharmacy curriculum should be adapted, in order to provide pharmacists with new knowledge and skills to provide pharmaceutical care services. This study used a modified Delphi technique to define objectives and topical outlines for a pharmaceutical care course on a pharmacy curriculum.
\end{abstract}

Methods: A modified Delphi process was used to determine a consensus among proposed course objectives and topical outlines. The preliminary phase of the study included a compilation of prospective objectives and outline topics on which to structure informational flow through the Delphi. A two-round modified Delphi process were completed by the participants in the study. The Delphi questionnaire was organized using six domains: the theoretical program foundation; recommended for teaching literature; instructional and educational objectives of the program (course structure); teaching methods; knowledge, skills and professional values considered; and students' performance assessments. Nineteen items for evaluation within the referred domains were considered.

Results: Consensus was achieved among 15 participants regarding 10 objectives, and eleven topical outlines related to pharmaceutical care teaching in an undergraduate pharmacy course. Despite this favorable valuation and considering the qualitative evaluations provided by the participants, it was believed appropriate to analyze the recommendation for the inclusion of literature for the teaching of the course in Spanish language (73\%). It resulted in a project proposal for the elaboration of a book by a group of authors from all the faculties of pharmacy in the country.

Conclusion: A Delphi expert panel achieved consensus on topical outline and objectives for a pharmaceutical care course. The results of this study can be used to underline the didactic guidance for pharmaceutical care teaching and learning useful for future pharmacy curriculum upgrades.

Keywords: Delphi questionnaire, Pharmacy education, Pharmaceutical care

Correspondence: alina.martinez@uam.es

${ }^{1}$ Facultad de Formación de Profesorado y Educación, Universidad Autónoma

de Madrid, Ciudad Universitaria de Cantoblanco, c/ Francisco Tomás y

Valiente, 3, 28049 Madrid, Spain

${ }^{2}$ Ex - Pharmacy Department Director, Universidad de Oriente, Santiago de

Cuba, Cuba

(c) The Author(s). 2021 Open Access This article is licensed under a Creative Commons Attribution 4.0 International License, which permits use, sharing, adaptation, distribution and reproduction in any medium or format, as long as you give appropriate credit to the original author(s) and the source, provide a link to the Creative Commons licence, and indicate if changes were made. The images or other third party material in this article are included in the article's Creative Commons licence, unless indicated otherwise in a credit line to the material. If material is not included in the article's Creative Commons licence and your intended use is not permitted by statutory regulation or exceeds the permitted use, you will need to obtain permission directly from the copyright holder. To view a copy of this licence, visit http://creativecommons.org/licenses/by/4.0/ The Creative Commons Public Domain Dedication waiver (http://creativecommons.org/publicdomain/zero/1.0/) applies to the data made available in this article, unless otherwise stated in a credit line to the data. 


\section{Background}

Since the concept of Pharmaceutical Care was announced from United States, this move has become an influential procedure of practice for many pharmacists around the World [1]. Pharmaceutical care is a professional practice that has arisen to meet the social need to prevent, identify, and solve drug therapy problems (DTP) and, therefore, reduce drug-related morbimortality $[2,3]$. DTP is any unwanted incident related to medication therapy that actually or potentially affects the desired goals of treatment [4]. DTP is an important public health problem and has been heightened in recent years [5]. Relatively $28 \%$ of all emergency department visits and 5 to $10 \%$ of all hospital admissions are drug related [6, 7]. The estimated annual cost of drug-related morbidity and mortality resulting from nonoptimized medication therapy for the United States of America was $\$ 528.4$ billion, equivalent to $16 \%$ of total US health care expenditures in 2016 [8]. Thus, DTPs represent a great challenge in the healthcare system as a result of increased patient morbidity, mortality, and healthcare costs [9]. In this stage, pharmaceutical care emerges as a patient-centered practice, in which the pharmacist assumes responsibility for the patients' pharmacotherapeutic needs and collaborates with other members of the health-care team, becoming then co-responsible for the outcomes of their pharmacotherapy [10].

Pharmacy education around the world is witnessing a process of transformation leading to perform pharmacists capable to provide pharmaceutical care [11-13]. Profound curricular changes have occurred in countries like Australia, Chile and The United States of America, developing a patient centered care professional practice $[14,15]$. But, even today, pharmacy education continues to be a barrier for the implementation and development of the pharmaceutical care [16]. As long as, how to implement the pharmaceutical care in a pharmacy curriculum is an unanswered question in some countries around the world. In addition, pharmacy students have difficulties with the practice of pharmaceutical care, despite having extensive knowledge on medicines, especially in developing countries $[17,18]$.

The pharmacy curriculum should be adapted, in order to provide pharmacists with new knowledge and skills. In most countries this change is taking place but not in a very structured manner [19]. Fresco and Silva described an example of pharmaceutical care teaching experience showing a description of a course syllabus, methods and teaching evaluation tools employed that demonstrated to motivate students toward this new practice and prepare them to increase their practical skills and clinical competences [20]. Furthermore, Fernández-Llimos and Nunes da Cunha designed a coding tree to classify pharmacy practice teaching topics, they included 110 pharmacy schools with 1703 pharmacy practice syllabus related to the pharmacy practice area, nonetheless, according to the authors, other studies are necessary to note the teaching of these curricular topics [21]. Recently, Arason et al., refers this type of learning more challenging than just learning content to repeat or apply at a later time. It is necessary to personalize this learning and make the practice of pharmaceutical care "real" for students. How do we facilitate the incorporation of Pharmaceutical Care and Pharmacists Patients`Care Process (PPCP) into our students' professional identity development was a question stated by the same author, and the proposal method is to introduce the PPCP early in the curriculum and link it to aspects that the profession students are familiar with, similarly, this approach was described by MartinezSanchez in 2009 [22, 23].

Being the pharmaceutical care one of the four areas defined by the International Pharmaceutical Federation's Global Competence Framework, the curriculum redesigned scheme is a priority task to perform a pharmaceutical workforce capable to contribute significantly to the appropriate use of medicines through research and by active participation in pharmaceutical care in collaboration with patients and other health care professionals [24, 25].

In 2005, the Cuban Government adopted inventiveness to inspire pharmacists to apply this new professional practice, including pharmaceutical care in the Cuban pharmacy legislation. Recommendations for didactic and assessment chances concerning incorporation of pharmaceutical care into the pharmacy curriculum, and the foundation for this emerging area of curriculum were included. In 2017, the Cuban Council on Higher Education stated a new pharmacy curriculum, consisting on pharmaceutical care to be considered as an eligible topic into the framework of a self-obligatory basic curriculum according to the necessities related to the social and geographical context university [26]. Nevertheless, limited published guidance is available on curricular structures, determining curricular objectives, topics and skills for pharmaceutical care in the Cuban pharmacy education system.

The Delphi Technique is a method designed to attain consensus of ideas of a group of experts through a series of intensive surveys interspersed with controlled belief feedback [27]. The basic argument of the Delphi research technique towards a pharmacy curriculum improvement, is entrenched in some form of general agreement and consensus regarding the core ingredients and components of the subsequent framework. Given the current status of implementing pharmaceutical care practice and education in developing countries, and the absence of generally based guidelines, the search for 
consensus and a point of departure in issues on clinical pharmacy education that will better serve developing countries is therefore justified through the use of this technique [28, 29]. Many studies support their developing and informing curriculum, thus, this technique have been found useful in curriculum development in business, nursing, medicine, agriculture, and technology along with environmental education [30]. The aim of this modified Delphi study was to determine objectives and topical outlines for a pharmaceutical care course on a pharmacy curriculum.

\section{Method}

This study used a modified Delphi technique to obtain consensus for undergraduate pharmaceutical care course determination of objectives and topic outlines on a pharmacy curriculum. The study site was the University of Oriente Pharmacy Department in Santiago of Cuba (Cuba).

\section{Delphi expert panel}

Pharmacy professors from seven national and foreign pharmacy schools and pharmaceutical organizations were invited to take part in this study. Participants from United State of America, Chile, Spain and United Kingdom were considered due to the recognized experiences of these countries in clinical and pharmaceutical care education and practice. The aim of the study was explained in the invitation letter. Consent for participation in the study was obtained by e-mail.

A call for participants was sent via email to members of the International Pharmaceutical Federation (FIP), American Association of Clinical Pharmacy (AACP), European Society of Clinical Pharmacy (ESCP), Iberian and Latin American Pharmaceutical Organization (Spanish OFIL), and the Cuban Pharmacy Association. We selected 15 pharmacy professors who had a background from at least three of the following criteria (some represented more than a few criteria): 1) Accreditation Council for Pharmacy Education membership. 2) Chaired or led a study or project of a school's PharmD and/or Pharm. BSc program, 3) Served as an officer for a pharmacy education evaluation-related special interest group (SIG) within a professional organization, 4) Have authored a peer-reviewed publication focused on clinical pharmacy competence education. The establishment of the criteria was led by the literature [31-35]. Teachers who are not PharmD and/or are not involved in clinical pharmacy teaching were excluded. Expert coefficient competence ' $K$ ' was calculated, which is considered a rate of the level of competence in a constituent panel of experts. In this study greater than 0.8 was considered high and for the group of coefficient ' $\mathrm{k}$ ' low was less than 0.7 [36].
In Cuba, pharmacy students undergo five years of undergraduate training before graduating as BSc. Pharm. Cuban pharmaceutical programs include both basic education on chemical, physiology and biological sciences and pharmaceutical practice at the community and hospital settings. In addition, to funding a clinical pharmacy training disciplines like Anatomy and systems-based pharmacology and therapeutics are included in a modularized and integrated curriculum. To perform a pharmacist capable to provide pharmaceutical patientcentered services a Social Pharmacy discipline was introduced in the curriculum. Enquiries concerning drug information, patient counselling, drug-related problems, and compliance are analyzed offering a 120-h internship to pharmacy practice $[37,38]$. In short, a pharmacy student receives formal education about clinical pharmacy and pharmaceutical care during the third and fourth year and clinical pharmacy training (usually from the fourth to the fifth year). Even though there is not a Cuban guideline on which undergraduate pharmaceutical care education or training is based. However, each academic institution chooses their own curriculum and appoint subjects related to clinical pharmacy and pharmaceutical care education according to its geographical health necessities [39]. After graduation pharmacists are registered as public practitioners and appointed to work at the public services as community or hospital pharmacists for there is no private opportunity in the Cuban Health System. Few opportunities to work in the pharmaceutical industry happen. All pharmacists are compelled to fulfil a social service during the first two years. After, they have some opportunities to be eligible to postgraduate programs such as Master or Doctor in Pharmaceutical Sciences; pharmaceutical internship programs are nonexistent.

\section{Delphi survey development}

The preliminary phase of the study included a compilation of prospective objectives and outline topics on which to structure informational flow through the Delphi. A bibliography examination was conducted on three pharmacy education-related journals: the American Journal of Pharmaceutical Education, Pharmacy Education, and Journal of Pharmacy Practice and Education. All journals were queried using the examination terms "pharmaceutical care", "pharmacy education" and "curriculum" to categorize potential issues of interest. In addition, the books entitled "Pharmaceutical Care Practice" and "Pharmaceutical Care Practice: The Clinician's Guide" by Cipolle, R., Strand, L., Morley, P. were reviewed [40, 41]. These publications were selected for the organizational and curricular approach because it provided guidance on pharmaceutical care syllabus for pharmacists theoretical and practical training. The search 
was limited to English or Spanish written articles issued from September 1st, 2001 to January 1st, 2017. We selected the year 2001 as the starting line of the search time because the Cuban Pharmacy curriculum named "Program C1" was initiated at the beginning of 2001, for topics related to clinical pharmacy and pharmaceutical care practice were officially included in Cuban pharmacy education.

Course objectives and topics were obtained from the pertinent literature. Moreover, researcher members from the "Manuel F. Gran" Center for the Study of Higher Education at the University of Oriente in Santiago de Cuba, Cuba were informally invited to contribute course objectives/topic from their pedagogical approach. This was done to enhance contributions from a didactic point of view toward ensuring consistency in terms of the teaching relationships established between objectives, subjects and methods as didactical categories within curricular design processes. A final list of objectives and topics were structured into three subjects with their respective proposals for teaching methods.

Accordingly, the Delphi questionnaire was organized using six domain structure adopted from the Cuban Ministry of Higher Education Guideline to design a teaching program, named: about the theoretical program foundation; recommended for teaching literature; instructional and educational objectives of the program (course structure); teaching methods; knowledge, skills and professional values considered; and students performance assessment. Nineteen items for evaluation within the referred domains were considered (Additional file 1).

Potential pharmacy professors who could serve as consultants in a pilot questionnaire evaluation were identified using National Commission for Pharmacy Education membership listservs obtained from the Vocational Training Department at the Ministry of Higher Education. Furthermore, potential pharmacists were identified from the professional pharmacist' register from Santiago de Cuba city. The questionnaire developed was reviewed by the authors for topic and layout and then piloted with two pharmacology professors from Havana University, and two community pharmacists developing clinical pharmacy activities from Santiago of Cuba, who were not included in the subsequent study panel. For the pilot study the questionnaire explaining purpose and requesting opinions related to understanding of pharmaceutical and pedagogical terms as well as clarity in questions structuring was delivered via email. This resulted in the rewording of a 'pharmacist with a wide profile'; this Cuban pedagogical definition according to which a professional profile is linked to a broad basic training [42]. Other modifications were not required.

\section{Delphi survey process}

The Delphi technique was used to attain a consensus on the objectives and topic outline for a pharmaceutical care course in a pharmacy curriculum. The Delphi method is a consensus-based technique that offers a systematic method of collecting and aggregating informed judgments from a group of experts via several iterations. Controlled feedback from successive rounds encourages participants to reassess, alter and/or develop opinions [43]. The Delphi process depends on the identification and use of specialists within the subject area. Delphi process does not require a random sample and that the qualities of the panel members are more significant than the number of persons on the panel.

The Delphi technique has been applied widely in diverse areas of scientific research [44]. Similarly, Delphi studies have been valuable in educational settings in forming procedures, standards, and in predicting tendencies [45]. In addition, numerous studies endorse the use of Delphi technique in pharmacy curriculum foundation [46-48].

A two-round modified Delphi process was completed by the participants in the study. We provided a base of objectives and topics recovered from the literature. In addition, a proposal of basic teaching literature was sent. Invitations were sent via e-mail, with the explanation of the study and the assurance of their participation anonymity.

The questionnaire was divided into two sections. Rounds included a description of the targets and approval for participation and instructions for evaluation. The first section registered demographic information: age, gender, professional qualification, years of work experience in pharmacy, teaching experience in clinical pharmacy and/or pharmaceutical care. Objectives and topics were assessed across each of the questionnaire domains and its items using the 5-point Likert scale indicating strength of importance for each objective ( $5=$ extremely suitable, $4=$ very suitable, $3=$ moderately suitable, $2=$ slightly suitable, and $1=$ not at all suitable). For the first round, respondents were given a chance to suggest modifications to current objectives/topics within each domain for evaluation.

Responses to the questions asked in the first iteration were synthesized and used for the second round. Only the items or points where consensus was not reached in the first stage were included in this round. The participants were asked to reconsider their scores having studied the whole panel's anonymized responses. They were provided with the following: (1) median and interquartile range of the whole panel's response for each definition or scenario; (2) comments made by individual (anonymous) participants together with the associated score; and (3) their own score relating to an item or definition. The 
inclusion of the participants' comments and a summary of their responses increase the number of reasoned responses and decreases the number of rounds required in order to reach consensus.

\section{Data analysis}

Statistical data was analyzed using the automated system "Delphi", on a work platform in Excel for Windows developed by Gómez et al. [49]. Descriptive statistics were used to illustrate respondents' demographic characteristics and group responses to each domain in all two rounds. According to Aronson and colleagues, there is a large number of definitions for the desired level of consensus in a Delphi process, but there is not an ultimate agreement [50].

In our case, with the dual objective of evaluating the appropriateness of the direct assignation of values to the responses of the ordinal scale in the evaluation of the items of the questionnaire by the judges participating in the Panel of Experts for their quantification, and analyze the suitability of the items raised in the Delphi method for the composition of the questionnaire the following steps are developed:

1. A summary table of the various weightings provided by the expert judges was drawn up assigning an assessment of the responses according to the criterion:

2. From the assessments, absolute response frequencies and accumulated frequencies were calculated, as well as the relative cumulative frequency, obtained from the quotient between the cumulative frequency of responses and the number of existing responses or number of experts, the latter expressed to two decimal places. It is interesting to observe how the relative accumulated frequency saturates its maximum value before the first category accumulating its maximum probability in all questions, so that the minimum indicator present will be "inadequate".

3. The cumulative relative frequencies were used to calculate the cut-off points and their respective indicator scales using the inverse standard normal values of each indicator's own cumulative probabilities in each question. To do this, we used the approximation to the nearest value of the Standard Normal curve of cumulative probability. It is necessary to indicate that for cumulative probability values equal to 1 , the corresponding inverse standard value is considered 3.5 as a practical reduction when asymptotic from 3.49. Similarly, for cumulative probability values equal to 0 , the inverse standard value shall be assumed to be equal to -3.5 . Having taken this into account, and in order to facilitate the work of calculating the inverse standard function corresponding to each cumulative probability value, the function relative to the inverse of the standard function was made use of through a computer spreadsheet software.

4. The "Average" column was added to the calculated values, obtained from the calculation of the average of the values found per row. Similarly, Cutoff Points are calculated as the average of the values of the inverse standard function for each of the scale values (columns). The value of Limit $\mathrm{N}$ was also determined, through the average of the Cut Off Points (whose result will be the same as the average of the averages of each category) and that will delimit the true ranges of interval to which pertains each category.

To determine the actual belonging said the ranges of each category for each item the value N-P was estimated, obtained as the difference of the limit value less the average value of each item. Finally, by comparing the $\mathrm{N}-\mathrm{P}$ value of each item with the cut-off points and range limits of each of the categories, the belonging of each of the items is precisely determined [51].

\section{Results}

Characteristics of responders participating in the panel process are shown in Table 1. Of the 15 respondents, 14 were male (93\%) and 1 was female (6\%). Respondents were also experienced in pharmacy teaching and practice (average of 20 and 15 years of professional experience and clinical pharmacy teaching experience, respectively). All experts were PharmD. Most of respondents presented $86 \%$ of the experts presented a high competence coefficient, $24 \%$ presented a medium competence coefficient (Table 2). The presented information of the coefficient ' $\mathrm{k}$ ' to the experts of the Delphi study concerning objectives and topic online for a pharmaceutical care course in a pharmacy curriculum was obtained from the information intreated from the participants, about their self-worth in terms of degree of knowledge on the theme and level of argumentation.

\section{Pharmaceutical care course}

After literature review was possible to identify three main steps of the pharmaceutical care process: patient's therapeutic necessities evaluation; design and establishment of a care plan and the evaluation of therapeutic goals. Three main subjects based on these steps were defined as follows: Integrated Pharmaceutical Care I, II and III. These subjects comprised the pharmaceutical care course designed. Issues such as: 1) understanding Pharmaceutical Care as a philosophy of practice; 2) pharmaceutical care process has a logical expression, in 
Table 1 Characteristics of respondents participating in panel

\begin{tabular}{|c|c|c|c|c|c|c|}
\hline Respondents & Age & Gender & $\begin{array}{l}\text { Professional } \\
\text { qualification }\end{array}$ & $\begin{array}{l}\text { Work experience } \\
\text { in pharmacy }\end{array}$ & $\begin{array}{l}\text { Teaching experience } \\
\text { in clinical pharmacy } \\
\text { and/or pharmaceutical } \\
\text { care }\end{array}$ & Country \\
\hline 1 & 54 & Female & PharmD & 21 & 14 & Cuba \\
\hline 2 & 60 & Male & PharmD & 20 & 15 & Cuba \\
\hline 3 & 65 & Male & PharmD & 18 & 11 & Cuba \\
\hline 4 & 55 & Male & PharmD & 22 & 15 & Cuba \\
\hline 5 & 49 & Male & PharmD & 20 & 20 & Cuba \\
\hline 6 & 57 & Male & PharmD & 16 & 12 & Cuba \\
\hline 7 & 60 & Male & PharmD & 19 & 13 & Cuba \\
\hline 8 & 54 & Male & PharmD & 20 & 14 & Cuba \\
\hline 9 & 55 & Male & PharmD & 21 & 14 & Cuba \\
\hline 10 & 59 & Male & PharmD & 23 & 19 & EEUU \\
\hline 11 & 62 & Male & PharmD & 20 & 17 & EEUU \\
\hline 12 & 58 & Male & PharmD & 26 & 10 & Chile \\
\hline 13 & 60 & Male & PharmD & 27 & 17 & Spain \\
\hline 14 & 52 & Male & PharmD & 17 & 15 & United Kingdom \\
\hline 15 & 58 & Male & PharmD & 23 & 20 & United Kingdom \\
\hline
\end{tabular}

Table 2 Expert competence coefficient " $k$ "

\begin{tabular}{llllll}
\hline Participants & Kc & Ka & K & \multicolumn{2}{l}{ Proficiency Level } \\
\cline { 5 - 6 } $\mathbf{1}$ & $\mathbf{0 . 6}$ & $\mathbf{0 . 8}$ & $\mathbf{0 . 7}$ & & Medium \\
\hline 2 & 1 & 1 & 1 & High & \\
3 & 0.9 & 1 & 0.9 & High & \\
4 & 0.9 & 1 & 0.9 & & Medium \\
5 & 0.7 & 0.8 & 0.7 & High & \\
6 & 0.8 & 0.9 & 0.8 & High & \\
7 & 0.7 & 1 & 0.8 & High & \\
8 & 0.9 & 0.9 & 0.9 & High & \\
9 & 0.9 & 0.9 & 0.9 & High & \\
10 & 0.8 & 0.9 & 0.8 & High & \\
11 & 1 & 0.9 & 1 & High & \\
12 & 0.8 & 1 & 0.8 & High & \\
13 & 1 & 1 & 1 & High & \\
14 & 0.7 & 0.8 & 0.7 & & Medium \\
15 & 0.9 & 1 & 0.9 & High & \\
\hline
\end{tabular}

$K$ Expert competence coefficient (scale of 0.25 to 1 )

$\mathrm{Ka}$ 'coefficient of argument' or foundation of expert opinion. It is obtained from assigning scores to a number of different sources of argument that could wield the expert

$K c$ 'coefficient of knowledge' or information that the expert on the subject or problem posed. It is calculated from the assessment made by the expert himself on a scale of 0 to 10 , multiplied by 0,1

$K=1 / 2(K c+K a)$ the clinical pharmacy method; 3) the clinical pharmacy method results to apply, the scientific method in the patient-drug relation managing; 4) the scopes of knowledge to curricular structure should be determined by patient needs and 5) the teaching process must consider the values inherent to the practice of pharmaceutical care were considered foundations to the pharmaceutical care course outline. For the most part of the respondents the theory and practical foundation course was considered very suitable (100\%).

\section{Course objectives and topical outline}

Literature review resulted in 15 possible objectives. The list was refined to 12 objectives after categorization and duplicate removal. These 12 objectives were tested in the first round. Two objectives were eliminated after detecting duplication in terms of skills according to Bloom's taxonomy. From a pedagogical point of view, two objectives were eliminated after detecting duplication in terms of skills according to Bloom's taxonomy. From a pedagogical point of view, these objectives included the same abilities and knowledge than other objectives considered in the final list. This list was refined to 10 objectives (16\% reduction) after the first round. Over the second round, nor change was proposed. Accordingly, the final accepted list (after the second round) consisted of 10 objectives distributed according to the skills and content corresponding to each of the three subjects described for the course. The Delphi process resulted in consensus, with $100 \%$ expert agreement with the topical outline after the completion of the first 
round. Eleven topical outlines were related to course objectives including principles of learning by emphasis on patient experiences related to medication, drugs and disease states and technical knowledge of how to provide pharmaceutical care practice, evaluation of drug - related problems and communications (Additional file 1). Topical outlines ranked suitable or very suitable were similarly associated to communication with physicians and clinical knowledge, developing an ethic framework, health-enhancing behaviors, avoid or reduce health risks associated to drug use.

After the second round, consensus was reached for all items in the questionnaire (Table 3). After the distribution in the different categories, it is observed that the

Table 3 Determination of images by the Inverse Standard Normal Curve and the Cutoff Points

Items Very suitable Suitable Unsuitable Averages N-P

About the theoretical and practical foundation

$\begin{array}{llllll}\text { Q1 } & 0.84 & 3.49 & 3.49 & 2.60 & -0.621 \\ \text { Q2 } & 3.49 & 3.49 & 3.49 & 3.49 & -1.511 \\ \text { Q3 } & -0,23 & 3.49 & 3.49 & 2.25 & -0.271\end{array}$

\section{Required and optional literature}

$\begin{array}{llllll}\text { Q4 } & 1.48 & 3.49 & 3.49 & 2.82 & -0.841 \\ \text { Q5 } & -0.10 & 1.48 & 3.49 & 1.62 & 0.359 \\ \text { Q6 } & 1.48 & 3.49 & 3.49 & 2.82 & -0.841\end{array}$

Instructional and educational objectives

$\begin{array}{llllll}\text { Q7 } & 3.49 & 3.49 & 3.49 & 3.49 & -1.51 \\ \text { Q8 } & 1.48 & 3.49 & 3.49 & 2.82 & -0.84\end{array}$

Course structure

$\begin{array}{llll}\text { Q9 } & 0.25 & 3.49 & 3.49 \\ \text { Q10 } & -1.13 & 3.49 & 3.49 \\ \text { Q11 } & -0.43 & 3.49 & 3.49 \\ \text { Q12 } & -1.55 & 3.49 & 3.49\end{array}$

\subsection{1}

1.95

2.18

1.81

Content

$\begin{array}{ll}\text { Q13 } & 3.49 \\ \text { Q14 } & 3.49 \\ \text { Q15 } & 0.62\end{array}$

Teaching methods

\begin{tabular}{clllll} 
Q16 & 0.84 & 3.49 & 3.49 & 2.60 & -0.621 \\
Q17 & 0.25 & 3.49 & 3.49 & 2.41 & -0.431 \\
Evaluation & & & & & \\
Q18 & 1.11 & 3.49 & 3.49 & 2.69 & -0.711 \\
Cut points & $\mathbf{1 . 0 4 8}$ & $\mathbf{3 . 3 7 8}$ & $\mathbf{3 . 4 9}$ & & \\
\hline
\end{tabular}

Decision rule:

Very suitable - 1048; Suitable - 3378; Not very suitable - 3,49

If $\mathrm{N}-\mathrm{P}<$ Cut-off point, then it is accepted as valid within the corresponding category

$\mathrm{N}$ : is the result of dividing the sum of the sums by the product of the number

of categories by the number of steps

$P$ : averages

$\mathrm{N}$ - P: Consulted experts given average value to each item evaluations provided by the members of the Panel of Experts are highly favorable to the items proposed in the questionnaire (Table 4).

Despite this favorable valuation and considering the qualitative evaluations provided by the participants, it was believed opportune to analyze the recommendation for the inclusion of literature for the teaching of the course in Spanish (73\%). It resulted in a project proposal for the elaboration of a book by a group of authors from all the faculties of pharmacy in the country.

\section{Discussion}

This modified Delphi study was a first effort to achieve consensus on a pharmaceutical care course in a curriculum for pharmacy students. The changeable training opportunities offered by pharmacy faculties and the lack of national guideline for an undergraduate pharmaceutical care curriculum was a motivation for performing this study. Every discussion around the Pharmacy education programs must begin with an interpretation of the profession's purpose within society. Societies funding favored status to professions because their members possess specialized knowledge. Intrinsic in this is a pact in which professionals use their expert capabilities in the best concern of the public. Consistent with Cuban economic and social reality the mission of the pharmacy profession is to deliver drugs to people with growing health care demands, and to help citizens achieve the best effects from pharmacotherapies, therefore enhancing health system [52]. The theoretical input of this

Table 4 Rank belonging to each of the items

\begin{tabular}{lll}
\hline Items & $\mathbf{N}-\mathbf{P}$ & Category \\
\hline Q1 & -0.621 & Very suitable \\
Q2 & -1.511 & Very suitable \\
Q3 & -0.271 & Very suitable \\
Q4 & -0.841 & Very suitable \\
Q5 & 0.359 & Very suitable \\
Q6 & -0.841 & Very suitable \\
Q7 & -1.511 & Very suitable \\
Q8 & -0.841 & Very suitable \\
Q9 & -0.431 & Very suitable \\
Q10 & 0.029 & Very suitable \\
Q11 & -0.201 & Very suitable \\
Q12 & Very suitable \\
Q13 & 0.169 & Very suitable \\
Q14 & -1.511 & Very suitable \\
Q15 & -1.511 & Very suitable \\
Q16 & -0.551 & Very suitable \\
Q17 & -0.621 & Very suitable \\
Q18 & -0.431 & Very suitable \\
\hline & -0.711 &
\end{tabular}


study lies in submitting a syllabus from a didactical perspective to implement pharmaceutical care on a pharmacy curriculum, considering topics and skills as a system.

On the other hand, the validation of the objectives of this program through the Delphi method comes to demonstrate the validity of the didactic interpretation of professional processes and their translation in the process of curriculum design, being another contribution of this study. The most important feature is to recognize pharmaceutical care as a philosophy. Pharmaceutical care is a generalist practice that can be applied in all setting: community, hospital, long-term care, and the clinic. It can be used to care for all types of patients with all types of diseases taking any type of drug therapy [53]. Since a pedagogical point of view: it is a professional way of performance. Subsequently, is not possible to include pharmaceutical care in the curriculum, merely altering name matter related clinical pharmacy by pharmaceutical care.

Through an iterative process of thoroughly assessing agreement amongst clinical and pharmaceutical care experts, 10 objectives reached consensus to be included in pharmaceutical care course designed. There was also considerable agreement on certain skills and abilities, regardless of the practice setting. All respondents were in agreement that designing individualized, culturally and therapeutic care plan, resolving drug-related problems, communication with health care professionals, implement a therapeutic plan, integration knowledge, skills, and personal caring into the provision and process of pharmaceutical care were very suitable. From the system perspective applied to the teaching and learning process it is not possible to separate the analysis and design of the objectives from the content established for teaching. Across the process, the clinical pharmacy method is applied, and the dialectic relation problem- method is showed. Consequently, knowledge, skills and professional values are included in this relation, and is feasible to determinate the highly aspect to transform into the teaching process; the method comes to be part of this content [54]. In line with pharmaceutical care practice the pharmacy student needs to be training to design, implement and monitoring a therapeutic plan to identify, resolve, and prevent drug related problems [55]. Therefore, these skills have been considered in the core of the objectives established for teaching pharmaceutical care.

For the student to appropriate a patient-centered performance logic the curriculum requires a sequence of objectives, which specify the expected outcomes of a pharmaceutical care process at each level. In this study, the process of curricular design of objectives and topical outline was dominated by the logic of the pharmaceutical care process taking into consideration each of its stages, starting with the evaluation of the patient's needs until the evaluation of its therapeutic results based on the improvement of the patient's quality of life. Identifying topical outlines support the professors in designing the framework, covering a course objective. Consequently, the topical outlines were designed and revised to support the course objectives. The surveyed participants showed their satisfaction with the topical outlines attached to course objectives like pharmaceutical care; introduction \& impact care planning as a component of the patient care process; drug therapy problems and tools for evaluating the quality of care offered. Consensus can be explained by the fact that respondents have a high experience level in clinical pharmacy practice and teaching, similarly, in the pharmaceutical care area there is some uniform worldwide theoretical framework around. In this regard, because items like inadequate clinical knowledge, and communication skills of pharmacists have been described as barriers have hampered the implementation of pharmaceutical care was an imperative design a broad and encompassing topical outline [56, 57]. Consistently, drug-related problems were widely considered in the topical outline. Being the core of the pharmaceutical care process scientific literature considers its inclusion, relevant in a pharmacy curriculum [58].

It has also been described that pharmacists, as givers to patient care, should evaluate data concerning untoward effects of drugs and be well competent to recognize and prevent these drug-related problems $[59,60]$. The pharmaceutical care concept accepts clinical interventions which lead to most favorable health outcomes. Identification, prevention or resolution of DTPs enhance patient's health results, and consequently, it should be incorporated within pharmaceutical care [61]. Thus, knowledge and training are essential requirements to competently deliver pharmaceutical care [62].

Using this curriculum framework, the pharmacy professor may now put these into operation for their specific subjects using existing resources, such as Hospital and Community position policies and papers. This study also confirmed other suggestion of our respondents for including some Spanish language bibliography in pharmaceutical care teaching. The findings of the study could facilitate students to have firm foundation of pharmaceutical care required for pharmacy practice, which they can build upon during their future training. It can help Social Pharmacy teachers to have specific outcomes which are clinically relevant in current clinical pharmacy practice.

The proposal to develop a basic book for the teaching of pharmaceutical care by a group of authors from all faculties of pharmacy is a challenging idea and at the same time an excellent opportunity to contextualize the teaching and practice of pharmaceutical care in the 
country. Since pharmaceutical care is an internationally accepted philosophy of professional practice, it is important that in each implementation strategy the particularities of the educational and health systems of each country are taken into consideration. Meanwhile, this new model will require profound transformations in terms of teaching methods, resources and the establishment of new forms of university-industry relations. Likewise, health systems will have to reform their models in terms of structures, processes and results to make room for a new professional who will be inserted with a concrete process to contribute to public health. All this knowledge, skills and attitudes should be taught in pharmacy schools and reinforced in clinical practice settings.

In addition, this methodology succeeds in deriving the key elements with regards to objectives and knowledge concerning pharmaceutical care process, besides it guides us about the pedagogical approach needed to design these elements in a pharmaceutical care teaching program. The objectives and topical outline identified in this study are dynamic and are possible to vary over time with progress of pharmaceutical care practice and may need to be reviewed in a near future.

Asking and answering fundamental questions required to define and validate curriculum design elements contained in a Pharmaceutical Care teaching program. Although defining and describing these elements were necessary steps toward developing a theoretical model to implement pharmaceutical care in pharmacy curriculum, additional questions remain and will need to be undertaken with future research. The inclusion criteria were another limitation of this study. Although they aimed to gather a group of individuals who were pharmacy education experts, our need for objective criteria that was available in accessible records may have resulted in the exclusion of individuals who had significant experience in pharmacy teaching.

\section{Conclusion}

This study provides the first evidence for pharmacy education curriculum modification toward pharmaceutical care teaching undergraduates based on the expert panel. This study has helped standard pharmacy practice knowledge requirements that are most relevant to present pharmaceutical care teaching, and essential in teaching pharmacy students. It can be used to underline the clinical significance for pharmaceutical care teaching and learning useful for future both, clinical practice and pharmacy education. Thus, it can facilitate students to gain a better understanding of how pharmaceutical care knowledge is operated in clinical practice. The results of this study can be used to underline the didactic guidance for pharmaceutical care teaching and learning useful for future pharmacy curriculum upgrades.

\section{Supplementary Information}

The online version contains supplementary material available at https://doi. org/10.1186/s12909-021-02583-1.

Additional file 1. Appendix 1. Definition of domains and items used in the questionnaire layout. Appendix 2. Final list consensus objectives related to topical outlines for undergraduate in pharmaceutical course.

\section{Acknowledgements \\ We would like to thank the pharmacy professors' group for taking part to the Delphi process.}

\section{Author's contributions \\ 'AMS'- The author alone is responsible for the content and writing of the article. The author(s) read and approved the final manuscript.}

\section{Funding}

Not applicable.

\section{Availability of data and materials}

All data generated or analyzed during this research are included in this article.

\section{Declarations}

Ethics approval and consent to participate

This study was approved with Doctoral Research Thesis status by the Cuban Ministry of Science, Technology and Environment. Registered at folio 127, number 3797 of the book by the Secretary of the National Commission of Scientific Degrees of the Cuban Ministry of Higher Education.

Consent for publication

Not applicable.

\section{Competing interests}

The authors report no conflicts of interest.

Received: 22 June 2020 Accepted: 26 February 2021

Published online: 16 March 2021

\section{References}

1. Berenguer B, La Casa C, de la Matta MJ, Martin-Calero MJ. Pharmaceutical care: past, present and future. Curr Pharm Des. 2004;10(31):3931-46. https://doi.org/10.2174/1381612043382521.

2. Cipolle RJ, Strand LM, Morley PC. Pharmaceutical Care Practice. New York: McGraw-Hill; 1998. p. 359.

3. Cipolle RJ, Strand LM, Morley PC. Pharmaceutical Care Practice: The Clinician's Guide. New York: McGraw-Hill Medical; 2004. p. 624.

4. Niriayo YL, Kumela K, Kassa TD, Angamo MT. Drug therapy problems and contributing factors in the management of heart failure patients in Jimma University Specialized Hospital, Southwest Ethiopia. PloS one. 2018;13(10): e0206120.

5. Nivya K, Sri V, Kiran S, Ragoo N, Jayaprakash B, Sekhar MS. Systemic review on drug related hospital admissions-a pubmed based search. Saudi Pharm J. 2015;23(1):1-8. https://doi.org/10.1016/j.jsps.2013.05.006.

6. Lopez A, et al. Drug-related problems at discharge programme consultants. Int J Pharm Pract. 2010;18:297-304.

7. Zed P. Drug-related visits to the emergency department. J Pharm Pract. 2005;18(5):329-35. https://doi.org/10.1177/0897190005280049.

8. Watanabe JH, Mclnnis T, Hirsch JD. Cost of prescription drug-related morbidity and mortality. Ann Pharmacother. 2018;52(9):829-37. https://doi. org/10.1177/1060028018765159.

9. Mehta U, Durrheim DN, Blockman M, Kredo T, Gounden R, Barnes Kl. Adverse drug reactions in adult medical inpatients in a south African hospital serving a community with a high HIV/AIDS prevalence: prospective observational study. Br J Clin Pharmacol. 2008;65(3):396-406. https://doi. org/10.1111/j.1365-2125.2007.03034.x.

10. Wiedenmayer K, Summers RS, Mackie CA. Developing pharmacy practice: a focus on patient care. 2006. http://www.who.int/iris/handle/10665/69399. Accessed 23 Jan 2020. 
11. Bhagavathula AS, Sarkar BR, Patel I. Clinical pharmacy practice in developing countries: focus on India and Pakistan. Arch Pharma Pract. 2014;5(2):91-4.

12. Odegard PS, Tadeg H, Downing D, Mekonnen H, Negussu M, Bartlein R. Strengthening pharmaceutical care education in Ethiopia through instructional collaboration. Am J Pharm Educ. 2011;75:134. https://doi.org/1 0.5688/ajpe757134.

13. Amariles $\mathrm{P}$, Sorio-Bedoya EJ, Cardona D. Teaching of pharmaceutical care in Latin America: a structured review. Farm Hosp. 2019;43(2):66-73.

14. Marriott JL, Nation RL, Roller L, Costelloe M, Galbraith K, Stewart P, Charman WN. Pharmacy education in the context of Australian practice. Am J Pharm Educ. 2008, 72(6):131. http://doi.org/ https://doi.org/10.5688/aj7206131.

15. Austin Z, Ensom MH. Education of pharmacists in Canada. Am J Pharm Educ. 2008;72(6):128. https://doi.org/10.5688/aj7206128.

16. Izham M, Mohamed I, Albert I, Zaheer-Ud-Din B. Social and Administrative Aspects of Pharmacy in Low- and Middle-Income Countries: Present Challenges and Future Solutions: Elsevier Inc; 2018. p. 48. https://doi.org/1 0.1016/C2016-0-00792-1. ISBN 978-0-12-811228-1

17. Toklu HZ. Pharmaceutical Education Vs. Pharmacy Practice: Do We Really Teach What They Need for Practicing? J Pharma Care Health Sys. 2015;2: e134. https://doi.org/10.4172/2376-0419.S3.e001.

18. Ghani K, Wasif G, Ghani M. Pharmacy teaching and practices problems in developing countries: review. Int J Pharm Teach Pract. 2010;1(1):11-7.

19. Storpirtis S. Perspectives and challenges in Pharmaceutical Care. Braz J Pharm Sci. 2012;48(4) v-v. https://doi.org/10.1590/S1984-82502012 000400001

20. Fresco P, Silva C. Pharmaceutical Care: a Teaching Experience. Pharmacy Education. 2011;11:129-55.

21. Fernandez-Llimos F, Nunes-da-Cunha I. Systematic coding of pharmacy practice educational contents. Pharm Care Esp. 2016;18(1):28-42.

22. Arosan J, Smith K, Hager K. Defining the Challenges in Teaching Pharmaceutical Care Practice: A Pharmacist Does What? Pulses. 2020; 3 de marzo. https://cptlpulses.com/2020/03/03/pharmacist-does-what/. Accessed 15 Jan 2020

23. Martínez-Sánchez AM. How to implement pharmaceutical care in the curriculum? The Cuban pharmacy education experiences. Lat Am J Pharm. 2009;28(1):100-2.

24. International Pharmaceutical Federation. Global Vision for a Global Pharmaceutical Workforce by Advancing Practice and Science through Transformative Education for Better Health care: "The FIP Vision for Education and Workforce". Nanjing: International Pharmaceutical Federation; 2016

25. International Pharmaceutical Federation. Quality Assurance of Pharmacy Education: the FIP Global Framework. The Hague. The Netherlands: International Pharmaceutical Federation; 2014

26. Sánchez AM. Bachelor of Pharmacy Degree in Cuba: New Educational Challenges. Am J Pharm Educ. 2011;75(1):3-5 Article 13.

27. Fefer JP, Stone SD, Daigle J, Silka L. Using the Delphi technique to identify key elements for effective and sustainable visitor use planning frameworks. Sage Open. 2016;6(2):1-16. https://doi.org/10.1177/2158244016643141.

28. Supapaan T, Low BY, Wongpoowarak P, Moolasarn S, Anderson C. A transition from the BPharm to the PharmD degree in five selected countries. Pharm Pract (Granada). 2019;17:1611

29. Ghayur M. Pharmacy Education in Developing Countries: Need for a Change. Am J Pharm Educ. 2008;72:94. https://doi.org/10.5688/aj720494.

30. Vallor R, Yates K, Brody M, et al. Educ Sci. 2016;6(4):42. https://doi.org/10.33 90/educsci6040042.

31. Penciner R, Langhan $T$, Lee R, Mcewen J, Woods RA, Bandiera G. Using a Delphi process to establish consensus on emergency medicine clerkship competencies. Med Teach. 2011;33(6):e333-9. https://doi.org/10.3109/01421 59X.2011.575903.

32. Traynor AP, Boyle CJ, Janke KK. Guiding principles for student leadership development in the Doctor of Pharmacy program to assist administrators and faculty members in implementing or refining curricula. Am J Pharm Educ. 2013;77(10):221. https://doi.org/10.5688/ajpe7710221.

33. Hsu C-C, Sandford BA. The Delphi Technique: Making sense of consensus 2007; 12(10):1-8.

34. Powell C. The Delphi technique: myths and realities. J Adv Nurs. 2003;41(4): 376-82. https://doi.org/10.1046/j.1365-2648.2003.02537.x.

35. Delbecq AL, Van de Ven AH, Gustafson DH. Group Techniques for Program Planning: A Guide to Nominal Group and Delphi Processes. Glenview: Scott, Foresman, and Co.; 1975. p. 10,89.
36. Zartha-Sossa J, Montes-Hincapié J, Toro-Jaramillo I, Hernández-Zarta R Método Delphi en estudios de prospectiva tecnológica: una aproximación para calcular el número de expertos y aplicación del coeficiente de competencia experta 'K'. Rev Bio Agro. 2017;15(1):105.115. https://doi.org/1 0.18684/BSAA(15)105-115.

37. Martínez AM. Atención Farmacéutica: Elemento Clave en el Diseño Curricular del Componente Clínico de la Carrera de Licenciatura en Farmacia. Santiago. Cuba: Universidad de Oriente; 2000.

38. Sedeño C, Pichardo M, Mateu L. Observatorio farmacéutico: conocer y transformar. Rev de la OFIL. 2005;15(4):33-8.

39. Suárez Pérez Y. Nuevo plan de estudio para la Licenciatura en Ciencias Farmacéuticas. Rev Cuba de Farm. 2018;51(2) http://www.revfarmacia.sld.cu/ index.php/far/article/view/223/115. Accessed 30 Jan 2020.

40. Cipolle RJ, Strand LM, Morley PC. Pharmaceutical Care Practice. New York: McGraw-Hill Health Professions Division; 1998.

41. Cipolle R, Strand L, Morley P. Pharmaceutical care practice: the Clinician's guide. New York: McGraw-Hill. Second Edition; 2012.

42. Horruitiner PM. La Universidad Cubana: el modelo de formación. 1st ed. La Habana: Felix Varela Press; 2006.

43. Schneider P, Evaniew N, Rendon JS, McKay P, Randall RL, Turcotte R, et al. Moving forward through consensus: protocol for a modified Delphi approach to determine the top research priorities in the field of orthopedic oncology. BMJ Open. 2016;6(5):e011780.

44. López-Gómez E. El método Delphi en la investigación actual en educación: una revisión teórica y metodológica. Educación XX1. 2018;21(1):17-40.

45. Green RA. The Delphi technique in educational research. SAGE Open. 2014; 4(2):1-8.

46. Covvey JR, Ryam M. Use of a Modified Delphi Process to Determine Course Objectives for a Model Global Health Course in a Pharmacy Curriculum. Am J Pharm Educ. 2018:82(8):6358.

47. Finn GM, Hitch G, Apampa B, Hennessy CM, Smith CF, Stewart J, et al. The anatomical society core anatomy syllabus for pharmacists: outcomes to create a foundation for practice. J Anat. 2018;232(5):729-38. https://doi. org/10.1111/joa.12787.

48. Koehler TC, Bok H, Westerman M, Jaarsma D. Developing a competency framework for pharmacy technicians: Perspectives from the field. Res Soc Adm Pharm. 2019;15:514-20.

49. Gómez Ravelo, I., de las Cuevas Milán, H. R., Fernández de Castro Fabre, A., y González Viera, D. Software evaluación de expertos por el método Delphi para el pronóstico de la investigación agrícola. (Spanish). 2013, 22(4), 81-86.

50. Vogel C, Zwolinsky S, Griffiths C, et al. A Delphi study to build consensus on the definition and use of big data in obesity research. Int J Obes. 2019;43: 2573-86. https://doi.org/10.1038/s41366-018-0313-9.

51. García-Ruíz M, Lena-Acebo F. Aplicación del Método Delphi en el diseño de una investigación cuantitativa sobre el fenómeno FABLAB. EMPIRIA. Revista de Metodología de Ciencias Sociales. 2018;40:129-66 doi: Empiria.40.2018. 22014/.

52. Jungnickel $P$, Hammer D, Kelley K. Addressing competencies for the future in the professional curriculum. Am J Pharm Educ. 2009:73(8):Article 156.

53. Dick TH. Informe del Grupo de Trabajo para implementar la Atención Farmacéutica en el curriculum. Pharm Care Esp. 1999;5:272.

54. Álvarez de Zayas C. La Escuela en la Vida. Editorial Universidad San Francisco Javier Sucre, Bolivia, 3th Ed; 1999.

55. Hepler CD, Strand LM. Opportunities and responsibilities in pharmaceutical care. Am J Hosp Pharm. 1990:47:533-43.

56. Apsy PV, Inamdar S, Rosy J, Kulkarni RV, Gazala K, Kavaya H, Bhuneshvari A, Sapna H. Assessment of Knowledge, Attitude and Practice of Community Pharmacist towards the Provision of Pharmaceutical Care: A Community Based Study. Ind J Pharm Prac. 2018;11:158-63 doi: 10.5530/ijopp.11.3.34.

57. Ahmed N AL-Wahibi N. Knowledge Attitude and Practice towards Pharmaceutical Care in Community Pharmacy in Saudi Arabia. Br J Med Med Res. 2016;15:1-9. https://doi.org/10.9734/BJMMR/2016/23920.

58. Zekan L, Mestrovic A, Perisin AS. Improving community pharmacists' clinical knowledge to detect and resolve drug-related problems in Croatia: a before/after survey study investigating the efficacy of an educational intervention. BMJ Open. 2020;10:e034674. https://doi.org/10.1136/ bmjopen-2019-034674.

59. Westerlund T, Marklund B. Assessment of the clinical and economic outcomes of pharmacy interventions in drug-related problems. J Clin Pharm Ther. 2009;34:319-27. 
60. Kovačević SV, Miljković B, Culafić M, et al. Evaluation of drug-related problems in older polypharmacy primary care patients. J Eval Clin Pract. 2017;23:860-5

61. Basheti IA, Armour $\mathrm{CL}$, Reddel $\mathrm{HK}$, et al. Long-term maintenance of pharmacists' inhaler technique demonstration skills. Am J Pharm Educ. 2009;73:32.

62. Bindoff I, Ling T, Bereznicki L. A computer simulation of community pharmacy practice for educational use. Am J Pharm Educ. 2014;78:168

\section{Publisher's Note}

Springer Nature remains neutral with regard to jurisdictional claims in published maps and institutional affiliations.

- fast, convenient online submission

- thorough peer review by experienced researchers in your field

- rapid publication on acceptance

- support for research data, including large and complex data types

- gold Open Access which fosters wider collaboration and increased citations

- maximum visibility for your research: over $100 \mathrm{M}$ website views per year

At BMC, research is always in progress. 